\title{
10 health stories that mattered: Mar. 28-Apr. 2
}

- Health Canada released a guidance document to permit fecal transplants outside clinical trials to treat cases of $C$. difficile that don't respond to conventional treatment with antibiotics. The guidelines are an interim measure while Health Canada works on establishing official regulations for fecal therapy.

- Health Canada is revising prescription information for drugs for attention deficit hyperactivity disorder to include stronger, clearer warnings about the risk of suicidal thoughts and behaviours. Still, the benefits of the drugs in managing the disorder outweigh the risks, states Health Canada.

- To combat childhood obesity, primary care practitioners should monitor children's growth (i.e., height, weight and body mass index) and recommend behavioural interventions to promote weight loss for children who are overweight or obese, according to new guidelines from the Canadian Task Force on Preventative Health Care. The guidelines recommend against routinely offering drugs or surgery to assist overweight and obese children lose weight.

- Canada imported \$6 million worth of products containing asbestos in 2014
— mostly brake pads and linings for vehicles - up from $\$ 4.9$ million in 2013. Exposure to asbestos in the workplace has been linked to deaths from mesothelioma, asbestosis and lung cancer.

- A task force will be created to examine factors contributing to the high number of mental health claims in the federal public service, which account for almost half of disability claims. The responsibilities of the task force, created as part of an agreement between the Public Service Alliance of Canada and the Treasury Board, are outlined in a memorandum of understanding that includes identifying ways to reduce stigma and better communicate issues about mental health in the workplace.

- The Ontario Homeopathy Act took effect Apr. 1, making the province the first in Canada to regulate homeopathy. Many medical professionals fear the act will lend legitimacy to a practice not based on science or clinical evidence.

- The Alberta government announced it will budget $\$ 3.4$ billion for health facilities over the next five years. The bulk of the funding, $\$ 2.7$ billion, will go toward new and ongoing construction projects, and the remaining money will be spent on maintenance and renewal.

- Ontario will introduce legislation to prevent breaches of private health information, announced Health Minister Eric Hoskins. This will include a new Electronic Personal Health Information Act and possible changes to strengthen the Personal Health Information Act.

- The growth of oil and gas development in northeastern British Columbia poses little risk to human health, according to a report commissioned by the BC Ministry of Health. Elevated air concentrations of some chemicals (e.g., formaldehyde, nitrogen dioxide and sulfur dioxide) were rare and occurred only in remote locations, states the report.

- Saskatchewan announced its plans to ban the use of indoor tanning beds for people under age 18 to decrease the risk of youth developing skin cancer later in life. The province is the only one in Canada without restrictions on indoor tanning. Roger Collier, CMAJ

CMAJ 2015. DOI:10.1503/cmaj.109-5037 